\title{
BACKUP DATABASE DENGAN MULTI MASTER REPLIKASI PADA KLUSTER SERVER
}

\author{
Ahmad Heryanto ${ }^{1,2}$ Yuyun Hartati ${ }^{3}$ \\ ${ }^{1}$ Laboratorium Jaringan Komputer dan Komunikasi Data, Sistem Komputer Universitas Sriwijaya \\ ${ }^{2}$ Teknik Elektro Universitas Sriwijaya \\ ${ }^{3}$ Teknik Komputer Univesitas Sriwijaya \\ hery@unsri.ac.id¹, yunha270395@gmail.com²
}

\begin{abstract}
ABSTRAK
Sistem database yang selalu tersedia merupakan kebutuhan mutlak pada insfrastruktur setiap organisasi. Data yang tersimpan harus terus tersedia pada saat dibutuhkan. Banyak hambatan dan gangguan dalam menyimpan data dalam suatu database. Hambatan dan gangguan tersebut tersebut bisa diakibatkan dari berbagai macam hal, seperti maintenance, kerusakan database, kerusakan media, data corruption dan bencana yang tak terduga (bencana alam). Oleh karena itu, diperlukan suatu Teknik replikasi yang baik untuk menjaga keutuhan data. Teknik replikasi Multi Master (Master-Master) telah diimplementasikan pada penelitian ini. Hasil penelitian ini, untuk melakukan replikasi 3 node server diperlukan waktu dengan rentang 0,1-0,2 detik.
\end{abstract}

Kata kunci: Replikasi, Database, Server, Multi Master, Kluster

\begin{abstract}
A database system that is always available is an absolute necessity in the infrastructure of every organization. Stored data must continue to be available when needed. Many obstacles and disruptions in storing data in a database. These obstacles and disruptions can be caused by various things, such as maintenance, database damage, media damage, data corruption, and natural disasters. Therefore, we need a good replication technique to maintain data integrity. Multi-Master Replication Techniques have been implemented in this study. The results of this study, to replicate 3 server nodes take a time span of 0.1-0.2 seconds.
\end{abstract}

Keywords: Replication, Database, Server, Multi Master, Cluster 


\section{PENDAhuluan}

Pada era digital seperti sekarang ini, kebutuhan akan database merupakan bagian yang tidak terpisahkan dari suatu organisasi, database digunakan oleh organisasi untuk menyimpan, dan mengolah data dengan rapi dan baik. Suatu organisasi memandang data sebagai aset yang bernilai tinggi dan tidak dapat digantikan dengan benda lain. Oleh karena itu, sangat penting sekali menjaga database tersebut dengan baik. Banyak hambatan dan gangguan dalam pengelolaan database. Hambatan dan gangguan tersebut tersebut bisa diakibatkan dari berbagai macam hal, seperti maintenance, kerusakan database, kerusakan media, data corruption dan bencana yang tak terduga (bencana alam)[1]. Hambatan dan gangguan pada suatu database, dapat mengakibatkan hilangnya data yang yang tersimpan di dalamnya. Kehilangan data ini dapat menyebabkan kerugian bagi pemilik.

Dalam mencegah kehilangan data pada suatu database biasanya digunakan teknik backup, Teknik backup yang dilakukan oleh kebanyakan orang adalah dengan menyalin file-file database kedalam suatu media penyimpanan tertentu seperti hardisk, ssd, dan flashdisk. Cara manual ini tidak efektif, karena harus dilakukan secara berkala dan terus-menerus secara manual. Jika suatu hari ada perubahan/penambahan/penghapusan terhadap data yang dilakukan pada media penyimpanan utama maka tidak akan mengubah data yang ada pada media penyimpanan cadangan, sehingga harus dilakukan update secara manual pada data data yang mengalami perubahan. Ketersediaan data yang baik secara realtime terkadang menjadi kebutuhan yang rumit pada masalah tertentu. Masalah tersebut berkaitan dalam hal kinerja sistem, jumlah pengaksesan data, serta lalu lintas jaringan yang dalam perkembangannya semakin bertambah padat. Hal tersebut memicu timbulnya teknologi replikasi data pada masa ini[2].

Proses replikasi data adalah suatu proses penggandaan data. Penggandaan data pada database sering dilakukan pada sistem database terdistribusi. Sistem database terdistribusi merupakan kumpulan kluster database yang dapat berpartisipasi dalam proses transaksi data pada database. Data dapat diakses pada kluster dengan menggunakan query tertentu. Terdapat beberapa hal yang mendasari dibentuknya kluster database, seperti pemakaian bersama (share), kehandalan (reliability), ketersediaan (availability) dan kecepatan pemrosesan query[2], [3]. Replikasi sangat berguna untuk melindungi ketersedian data yang akurat. Teknik replikasi yang baik untuk database adalah menggunakan teknik replikasi synchronous. Teknik ini dapat melakukan backup database secara realtime kepada semua node pada kluster server database. Kluster database pada penelitian ini menggunakan Galera Cluster. Galera Cluster menerapakan teknik replikasi multi-master dimana setiap node berperan sebagai master dan client dapat melakukan query insert, delete, drop ataupun update dari node manapun. Galera Cluster akan menjamin perubahan data pada suatu node akan memicu perubahan pada node lainnya secara realtime. Transaksi data pada suatu kluster database secara realtime dapat digunakan sebagai backup data pada suatu sistem database.

\section{TINJAUAN PUSTAKA}

\section{1. Database}

Istilah database berasal dari bidang Ilmu Komputer, yang menjelaskan tentang sekumpulan informasi yang disimpan dalam komputer secara sistematik dan terstruktur. sehingga data dapat disimpan dan diolah dengan menggunakan suatu program komputer. program komputer yang dipakai untuk database dikenal dengan database management system (DBMS). Banyak produkproduk DBMS yang popular digunakan pada bidang komputer, yaitu[4]

1. MYSQL

2. MariaDB

3. Oracle Database

4. PostgreSQL

5. MongoDB

6. MemSQL

7. Interbase

8. Dan lain sebagainya.

Data yang tersimpan di dalam database terdiri dari dua jenis, yaitu data yang terstruktur data dan data semi terstruktur. Oleh karena itu, data yang tersimpan di dalam database memiliki bentuk tabel-tabel yang saling berhubungan dimana setiap tabel terdiri dari baris dan kolom. Proses penyimpanan, pengolahan dan pengambilan data pada database menggunakan query. Query yang digunakan memiliki bentuk dan kombinasi khusus, bahkan pada beberapa DBMS query tersebut dapat dibuat menjadi suatu program batch khusus. Penggunaan query yang tepat akan menentukan performa, akurasi dan presisi data yang akan di retrieve.

\subsection{Kluster Database}

Klaster database merupakan kumpulan dari beberapa server database yang memiliki fungsi yang sama. Kumpulan server ini bisa dipandang sebagai satu kesatuan sistem database. Server-server database tersebut terhubung melalui jaringan komputer yang berkecepatan tinggi. Sebuah server database pada klaster dikenal dengan sebutan node. Node memiliki perangkat keras untuk mendukung komputasi (CPU, memory, disk, I/O dan lainlain) serta perangkat lunak (sistem operasi, aplikasi dan service) yang bekerja secara independen[5]. 


\subsection{Replikasi Database}

Replikasi database adalah teknik mengirimkan data yang tersimpan dalam suatu database ke dalam database yang berbeda. Replikasi bertujuan untuk membentuk salinan data pada suatu sistem database. Pada pelaksanaannya implementasi teknik replikasi pada sistem database akan berbeda, tergantung pada engine database yang digunakan. Secara umum jenis repikasi database terbagi menjadi dua kelompok, yaitu replikasi Sychronous dan Asychronous[2].

1. Replikasi Sychronous

a. Proses berlangsung secara real time antara master dan juga slave.

b. Penulisan data pada penyimpanan master dan slave secara bersamaan

c. Menyediakan data recovery yang konsisten

2. Replikasi Asychronous

a. Replikasii data berlangsung bertahap/perbagian.

b. Data akan ditulis pada penyimpanan master terlebih dahulu, kemudian proses replikasi dilakukan di slave.

c. Tidak ada jaminan data aktual yang terdapat pada master akan sama dengan data pada slave.

Replikasi database dapat dilakukan dengan tiga cara yang berbeda, antara lain[2];

1. Snapshot Replication

Melakukan salinan data pada suatu database ke dalam server lain secara penuh,

2. Merging Replication Menggabungkan beberapa database ke dalam satu database.

3. Transactional Replication

Melakukan salinan database berdasarkan bagian tertentu yang mengalami perubahan

\section{METODE PENELITIAN}

Penelitian ini menggunakan perangkat keras (hardware) dan perangkat lunak komputer (software). Adapun kebutuhan hardware dan software yang akan digunakan dalam penelitian adalah sebagai berikut:

\subsection{Perangkat keras (hardware)}

Pada penelitian digunakan komputer server dengan prosesor 64 Core, Memori 126 GB dan kapasitas Hardisk sebesar 1TB. Adapun spesifikasi hardware dapat dilihat pada gambar berikut ini.

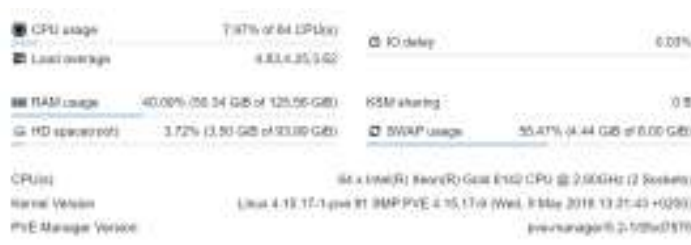

Gambar 1. Spesifikasi Perangkat Keras

Hardware ini digunakan untuk membentuk cluster komputasi dari database server, Server hardware ini akan digunakan untuk menjalankan software cloud computing, seperti proxmox atau vmware.

\subsection{Perangkat Lunak (Software)}

Penunjang lain dalam penelitian selain perangkat keras adalah sangat dibutuhkannya perangkat lunak dalam pembuatan cluster database.

1. Perangkat lunak virtualisasi yang digunakan untuk membuat virtual machine adalah Proxmox.

2. Perangkat lunak Ubuntu Server 16.0 sebagai aplikasi yang digunakan dalam pembuatan komputer server.

3. Pembuatan Clustering menggunakan $M y S Q L$ Cluster Database dengan Galera Cluster sebagai toolsnya.

Peneliti membuat cluster database menggunakan MySQL galera cluster dengan jumlah 3 buah node yang masing-masing node berperan sebagai server pada dengan Ubuntu Server 16.0 sebagai sistem operasinya. Perancangan desain jaringan dalam pembangunan multimaster database menggunakan galera dilakukan dengan jaringan virtual yang terhubung dengan jaringan fisik.

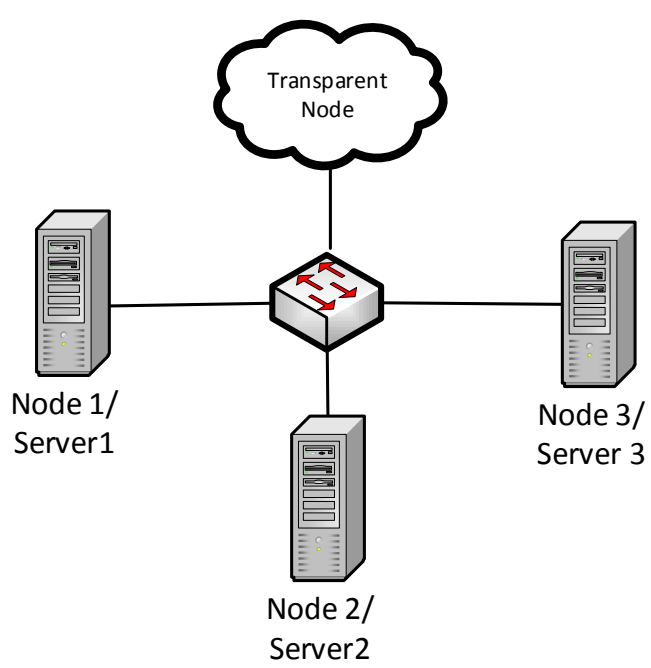

Gambar 2. Toplogi jaringan sistem replikasi database 
Universitas AL Asyariah Mandar

Topologi jaringan yang digunakan ditunjukan pada gambar di atas. Sistem replikasi terdiri dari 3 buah node yang semuanya berperan sebagai server, masingmasing server mempunyai hak untuk mereplikasi database dengan izin (password). Untuk pengalamatan jaringan pada sistem ini, server 1 dikenakan pengalamatan dengan IP Address 192.168.70.11/24, server 2 dengan IP Adress 192.168.70.21/24 dan server 3 dengan IP Adress 192.168.70.31/24.

Tabel 1. Rancangan Server

\begin{tabular}{|c|c|c|c|c|c|}
\hline SERVER & PROSESOR & CPU & RAM & HARDDISK & INTERFACE \\
\hline Server1/Node1 & $3.4 \mathrm{GHz}$ & 4 & $15 \mathrm{~GB}$ & $100 \mathrm{~GB}$ & LOCAL \\
\hline Server2/Node 2 & $3.4 \mathrm{GHz}$ & 4 & $15 \mathrm{~GB}$ & $100 \mathrm{~GB}$ & LOCAL \\
\hline Server3/Node 3 & $3.4 \mathrm{GHz}$ & 4 & $15 \mathrm{~GB}$ & $100 \mathrm{~GB}$ & LOCAL \\
\hline
\end{tabular}

Tabel 1 menjelaskan rincian spesifikasi server, mulai dari RAM, Prosesor, Hardisk serta jaringan network yang digunakan oleh server-server database.

\subsection{Diagram Blok}

\begin{tabular}{|c|c|c|c|}
\hline $\begin{array}{l}\text { Install Virtual } \\
\text { Mesin }\end{array}$ & $\begin{array}{l}\text { Setup Server } \\
\text { Ubuntu } 16.04\end{array}$ & $\begin{array}{l}\text { Install SSH } \\
\text { Server }\end{array}$ & $\begin{array}{l}\text { Remote SSH } \\
\text { client Putty }\end{array}$ \\
\hline & & & $\nabla$ \\
\hline & $\begin{array}{l}\text { Uji Kluster } \\
\text { Database }\end{array}$ & $\begin{array}{c}\text { Multi Master } \\
\text { Database }\end{array}$ & $\begin{array}{l}\text { Setup MySQL } \\
\text { \& Galera }\end{array}$ \\
\hline
\end{tabular}

Gambar 3. Diagram Blok Jalannya Penelitian

Diagram Blok diatas menjelaskan tentang tahapan pembangunan sistem replikasi database yang akan dibuat, yakni;

1. Instalasi virtual machine pada proxmox dan buat maesin baru sebanyak 3 mesin yang akan jadi server dengan memasukan ip static pada setiap mesin.

2. Masing-masing server basis data akan dilakukan instalasi sistem operasi Ubuntu Server 16.04

3. Instalasi ssh supaya sistem bisa di-remote menggunakan aplikasi Putty.

4. Instalasi mysql dan galera pada setiap server dengan melakukan konfigurasi pada setiap server.

5. Buat kluster pada server 1 dan gabungkan server 2 dan 3 menjadi satu cluster yang sama dengan server 1

6. Setelah tergabung, uji setiap cluster untuk memastikan sudah tergabung dengan mencoba memodifiksi database.

7. Implementasi ke cloud dengan menggunakan ip yang disediakan dan di-remote melalui putty.

Mode replikasi yang digunakan adalah replikasi multi master. Replikasi multi master dapat membuat proses replikasi berjalan secara full duplex. Proses pertukaran data pada database server akan tersinkronisasi secara realtime pada setiap node. Jika salah satu node pada kluster database melakukan perubahan data (Insert, Delete, Update) maka perubahan tersebut akan terjadi juga pada semua node pada kluster tersebut.

\section{HASIL DAN PEMBAHASAN}

Penelitian tentang replikasi database server dengan metode multi master telah berhasil dilakukan, replikasi telah bekerja sebagaimana mestinya. Kluster komputer dapat saling bekerja sama dalam melayani setiap query request dari client database.

Kluster server database terdiri dari node-node komputer yang saling bekerja sama dan dihubungkan melalui jaringan komputer yang berkecepatan tinggi. Adapun insfrastruktur jaringan dan server ditunjukan pada gambar berikut ini.
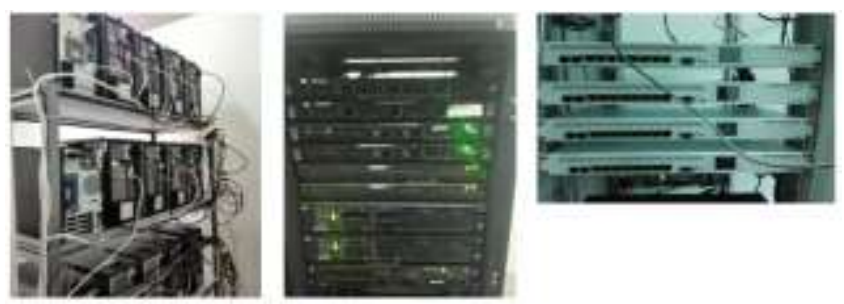

Gambar 4. Insfrastruktur Jaringan dan Server Penelitian

Adapun node yang telah terimplementasi dalam kelompok kluster database memiliki spesifikasi seperti pada gambar berikut ini.

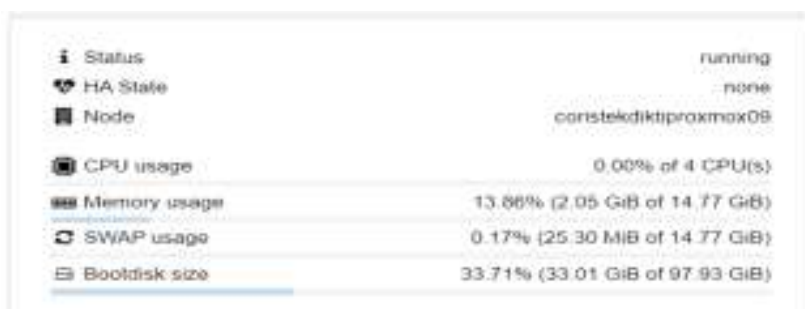

Gambar 5. Spesifikasi node pada kluster database

Kluster node akan bekerja secara mandari dan otonom selama layanan database bekerja, replikasi akan terus terjadi setiap ada perubahan data pada masing-masing node yang digunakan. Adapun penggunaan resource CPU pada kluster ditunjukan pada gambar berikut ini.

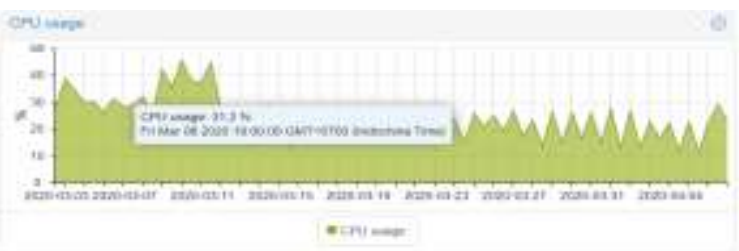

Gambar 6. Statistik CPU usage per host 
Statistik penggunaan resource CPU selama 1 bulan penelitian adalah $10 \%-45 \%$. Pada saat proses replikasi terjadi menunjukan bahwa resource CPU tidak terbebani secara penuh untuk melakukan replikasi. Sedangkan penggunaan memori rata-rata $13 \mathrm{~GB}$ dengan presentase +$25 \%$. Data penggunaan memori ditunjukan pada gambar berikut ini.

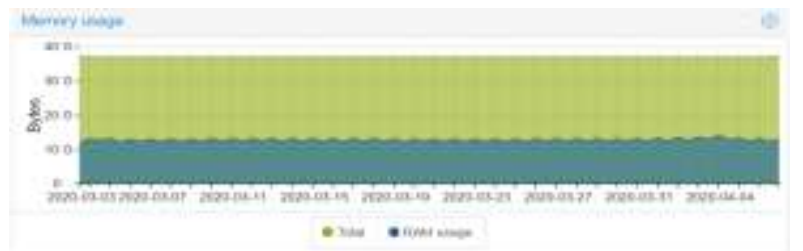

Gambar 7. Statistik Memory Usage

Proses replikasi harus ditopang oleh insfrastruktur jaringan yang handal dan berkecepatan tinggi. Pada percobaan penelitian kami menggunakan link fiber optic untuk menghubungkan node-node database. Sehingga dihasilkan kecepatan dan performa network yang terbaik. Adapun statistik penggunaan link komunikasi pada kluster database ditunjukan pada gambar berikut ini.

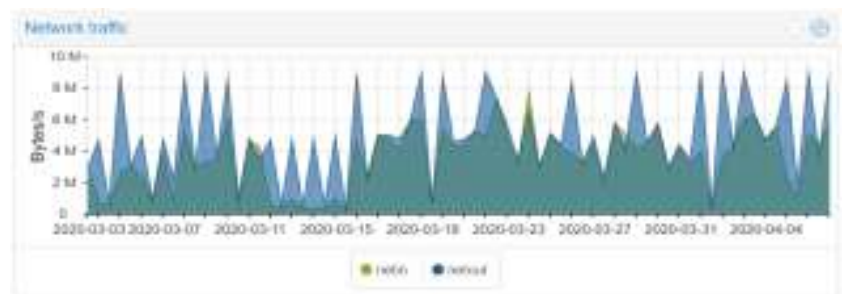

Gambar 8. Statistic Network Traffic

Waktu yang diperlukan untuk melakukan replikasi adalah waktu proses pengiriman data dari salah satu node (insert, delete, modif) kepada member kluster pada insfrastruktur database server. Waktu yang dibutuhkan untuk melakukan replikasi dengan 3 node adalah kurang dari 0.2 detik. Proses replikasi di ilustrasikan seperti gambar berikut ini.

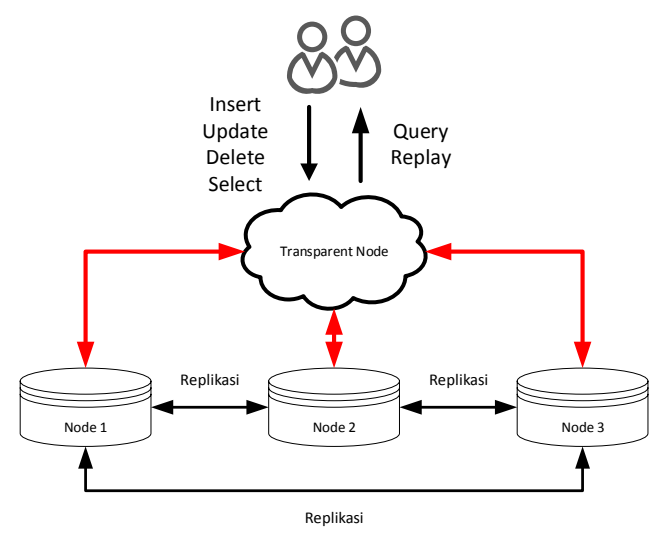

Gambar 9. Proses Replikasi
Setiap ada perubahan data dari salah satu node, maka perubahan data tersebut akan langsung direplikasi kepada node-node server lainnya. Waktu yang diperlukan oleh masing-masing node untuk melakukan replikasi adalah 0.10.2 detik.

Tabel 2. Waktu Replikasi Master-Master

\begin{tabular}{|c|c|c|c|c|c|}
\hline No & Kueri & Node1 & Node2 & Node3 & $\begin{array}{c}\text { Rata- } \\
\text { Rata }\end{array}$ \\
\hline 1 & Node1 & 0 & 0.2 & 0.1 & 0.1 \\
\hline 2 & Node 2 & 0.2 & 0 & 0.1 & 0.1 \\
\hline 3 & Node3 & 0.1 & 0.2 & $0 \mathrm{~s}$ & 0.1 \\
\hline \multicolumn{2}{|c|}{ Rata-Rata } & 0.1 & 0.13 & 0.06 & $0.29 \backslash 0.3$ \\
\hline
\end{tabular}

\section{KESIMPULAN}

Kesimpulan yang diperoleh dari penelitian ini adalah sebagai berikut:

1. Replikasi mode multi master dapat menjadi solusi untuk ketersediaan data.

2. Replikasi yang tersinkron dengan baik membuat semua server memiliki data yang mutakhir.

3. Layanan database selalu tersedia pada saat client mengirimkan query request pada sistem kluster.

\section{DAFTAR PUSTAKA}

[1] N. Dhanujati and A. S. Girsang, "Data Center-Disaster Recovery Center (DC-DRC) for High Availability IT Service," in 2018 International Conference on Information Management and Technology (ICIMTech), Sep. 2018, pp. 55-60, doi: 10.1109/ICIMTech.2018.8528170.

[2] A. Heryanto and A. Albert, "Implementasi Sistem Database Terdistribusi Dengan Metode Multi-Master Database Replication," J. MEDIA Inform. BUDIDARMA, vol. 3, no. 1, pp. 30-36, Mar. 2019, doi: 10.30865/mib.v3i1.1098.

[3] "Remote disaster recovery system architecture based on database replication technology - IEEE Conference Publication."

https://ieeexplore.ieee.org/document/5544352 (accessed Apr. 14, 2020).

[4] R. Čerešńák and M. Kvet, "Comparison of query performance in relational a non-relation databases," Transp. Res. Procedia, vol. 40, pp. 170-177, Jan. 2019, doi: 10.1016/j.trpro.2019.07.027.

[5] "A high availability (HA) MariaDB Galera Cluster across data center with optimized WRR scheduling algorithm of LVS - TUN - IEEE Conference Publication." 
Jurnal Ilmiah Ilmu Komputer Vol. 6, No. 1, April 2020

(P) ISSN 2442-451X

Fakultas Ilmu Komputer

(O) ISSN 2503-3832

Universitas AL Asyariah Mandar

https://ieeexplore.ieee.org/document/7440452

(accessed Apr. 14, 2020). 